\title{
Association of biological maturation with the development of motor competence in Austrian middle school students-a 3-year observational study
}

\author{
Clemens Drenowatz ${ }^{1}$, Klaus Greier ${ }^{2,3}$ \\ ${ }^{1}$ Division of Physical Education, University of Education Upper Austria, Linz, Austria; ${ }^{2}$ Division of Physical Education, Private Educational College \\ (KPH-ES), Stams, Austria; ${ }^{3}$ Department of Sports Science, Leopold-Franzens-University Innsbruck, Innsbruck, Austria \\ Contributions: (I) Study conception and design: K Greier; (II) Administrative support: K Greier; (III) Provision of study materials or patients: K \\ Greier; (IV) Collection and assembly of data: K Greier; (V) Data analysis and interpretation: C Drenowatz; (VI) Manuscript writing: All authors; (VII) \\ Final approval of manuscript: All authors. \\ Correspondence to: Clemens Drenowatz. Division of Physical Education, University of Education Upper Austria, Kaplanhofstrasse 40, 4020 Linz, \\ Austria. Email: clemens.drenowatz@ph-ooe.at.
}

Background: Motor competence is an important component in the facilitation of an active lifestyle and is influenced by environmental and biological constraints. Biological maturation has been shown to affect participation in various forms of physical activity (PA) and sports but information on the association with motor competence and motor development remains limited.

Methods: A total of 212 (59\% male) Austrian middle school students ( $10.8 \pm 0.5$ years) were followed over 3 years. Participants completed annual anthropometric measurements along with the German motor test (Deutscher Motorik Test, DMT6-18) during a physical education lesson. Biological maturation was determined based on the estimated age at peak height velocity (APHV), as this has been shown to coincide with the onset of puberty.

Results: Earlier maturation was associated with higher body weight and lower motor competence in boys and girls. Cross-sectional associations between motor competence and biological maturation, however, were limited after adjusting for body weight. Longitudinal results showed a more pronounced weight gain and impaired development of motor competence late maturing boys. In girls, weight gain was more pronounced with early maturation but this did not affect the development of motor competence. It was further shown that endurance capacity already declined in this cohort while agility increased.

Conclusions: The results of this study confirm the previously reported association between biological maturation and body weight, which also affects motor competence. Nevertheless, late maturing boys appear to be at a greater risk for excess weight gain, which negatively affects the development of motor competence during early adolescence. In girls, the association between weight change and development of motor competence was less clear. Of additional concern is the decline in cardiorespiratory fitness already during early adolescence as low cardiorespiratory fitness is associated with an increased risk for various chronic diseases later in life.

Keywords: Adolescence; motor abilities; movement skills; physical fitness; puberty

Submitted May 31, 2019. Accepted for publication Sep 03, 2019.

doi: 10.21037/tp.2019.09.03

View this article at: http://dx.doi.org/10.21037/tp.2019.09.03 


\section{Introduction}

Physical activity (PA) has been identified as major contributor to health and well-being (1-3). As PA tracks from childhood into adolescence and adulthood $(4,5)$ there have been collective efforts to ensure sufficient PA in youth. Effects of various intervention strategies targeting higher PA in children and adolescents, however, have been limited (6) and recent estimations indicate that $81 \%$ of 11 to 17 -year-old do not meet current PA recommendations of 60 minutes of moderate-to-vigorous PA per day (7). In addition to the detrimental effects of insufficient PA on cardiometabolic, musculoskeletal and psychological health, low PA puts a significant burden on the health care system; an estimated 54 billion US\$ of global annual costs in direct health care have been attributed to insufficient PA (7).

Insufficient PA during childhood and adolescence has also been associated with a decline in physical fitness and motor competence in youth (8-10), which reflects the ability to perform goal-directed movements (i.e., locomotion, stability tasks, object control) (11). In fact, limited effects of various PA interventions have, at least partially, been attributed to low motor competence (12), as children and adolescents with low motor competence are generally less likely to engage in active free play (13). Low motor competence is further associated with disengagement from formal exercise or sports due to lower perceived competence and greater difficulties with learning new sport-specific skills (13-15). This is consistent with the social cognitive theory, that emphasizes the importance of self-efficacy for engagement in PA, particularly during adolescence (16). High motor competence during childhood and adolescence, on the other hand, has been associated with higher PA levels in adults (17), which indicates a direct and indirect pathway of motor competence with lifetime PA $(11,18)$.

Even though rudimentary motor skills (i.e., walking) develop naturally, the development of motor competence needs to be nurtured and is influenced by biological and environmental factors (19). Accordingly, biological maturation, which describes the progress towards a mature state has been shown to affect motor competence $(14,20)$. Despite the fact that biological maturation occurs in a predictable manner, there is a large individual variability in the timing and tempo of the maturational process, resulting in differences in size, shape, body composition as well as motor and cognitive performance in children and adolescents of similar age $(21,22)$. These differences are most pronounced during the pubertal years (14). The rapid physiological, psychological and behavioral changes along with increased social and economic independence during adolescence also make puberty a vulnerable time for behavioral change $(23,24)$. Given the importance of motor competence in the promotion of an active lifestyle, additional research on the association of biological maturation with the development of motor competence is warranted. The present study, therefore, examined the cross-sectional and prospective association between biological maturation and motor competence in Austrian middle school students over a 3 -year period.

\section{Methods}

A total of 7 middle schools in the federal state of Tyrol, Austria were randomly selected for participation. Due to the longitudinal nature of the study only students starting middle school (between 10 and 11 years of age) were eligible for participation, which resulted in 278 eligible participants. Data collection started in 2013 and participants were followed over a period of three years with annual measurements being taken between October and November. Parents received written information about the study via the participating schools and provided written informed consent. Oral consent was obtained from the participants at the time of data collection. The study has been carried out in accordance with the Declaration of Helsinki and procedures were approved by the University of Innsbruck Institutional Review Board, the school authorities of the federal state of Tyrol and the school board of the participating schools.

\section{Anthropometric measurements}

All measurements were taken during a regular physical education class. Body weight and height were measured by trained technicians with participants wearing gym clothes and barefoot. Specifically, body weight was measured to the nearest $0.1 \mathrm{~kg}$ with a gauged body scale (GRUNDIG ${ }^{\circledR} 3710$, Grundig AG, Nürnberg, Germany) and height was measured to the nearest $0.1 \mathrm{~cm}$ with a mobile stadiometer $\left(\mathrm{SECA}^{\circledR} 217\right.$, Seca, Hamburg, Germany). Body mass index (BMI, kg/m²) was calculated and converted to BMI percentiles (BMIPCT) using the German reference system (25). Subsequently, participants were classified as non-overweight or overweight/ obese using the $90^{\text {th }}$ percentile as cutpoint. 


\section{Motor competence}

Following anthropometric measurements, participants completed the "Deutsche Motorik Test" (German motor test, DMT 6-18) (26). The DMT 6-18 consists of 8 test items that assess flexibility, balance, agility, strength, power, speed and endurance. All tests (20 m sprint, backward balancing, sideways jumping, standing long jump, sit ups, push-ups, stand and reach test, 6-minute run) were completed after a standardized 5-minute warm-up in the respective school's gymnasium. The testing session started with the $20 \mathrm{~m}$ sprint and ended with the 6 -minute run. The remaining tests were performed at random order with instructions and practice trials provided as specified by the test manual. In addition to raw performance scores, ageand sex-standardized values were determined for each test item based on a German reference sample (26). The mean of these standardized scores was subsequently used as an indicator for total motor competence.

\section{Biological maturation}

Somatic growth parameters were used for the estimation of biological maturation. Maturity status was determined based on the estimated age at peak height velocity (APHV), as the onset of the adolescent growth spurt coincides with the onset of puberty (27). Years from APHV (i.e., maturity offset) were calculated using the following equations at each measurement time point (28):

$$
\begin{aligned}
& \text { Maturity Offset }_{\text {boys }}=-7.999994+ \\
& \{0.0036124 \times[\text { age }(\text { years }) \times \text { height }(\mathrm{cm})]\} ; \mathrm{R}^{2}=0.896
\end{aligned}
$$

$$
\begin{aligned}
& \text { Maturity Offset }{ }_{\text {girls }}=-7.709133+ \\
& \{0.0042232 \times[\text { age }(\text { years }) \times \text { height }(\mathrm{cm})]\} ; \mathrm{R}^{2}=0.898
\end{aligned}
$$

APHV was subsequently calculated $(\mathrm{APHV}=$ chronological age - maturity offset) and the time point with the smallest difference between chronological age and APHV was used for the analyses as the equations have been shown to be most accurate close to APHV (28). Subsequently participants were stratified into early, average or late maturers based on sex specific sample tertiles.

\section{Statistical analysis}

Descriptive statistics were calculated and data was checked for normal distribution in the total sample and the respective subsamples. Cross-sectional associations between biological maturation (indicated by estimated APHV) and body weight as well as motor competence were examined via Pearson correlation analyses. In addition, partial correlations, adjusted for BMIPCT, were calculated. The strength of the association was defined as weak $(0.3>r>0.1)$, moderate $(0.5 \geq \mathrm{r} \geq 0.3)$ or strong $(\mathrm{r}>0.5)$, for positive and negative correlation coefficients (29). Longitudinal associations between biological maturation and motor competence were examined via mixed linear models separately for boys and girls by maturity tertiles.

\section{Results}

A total of 212 middle school students (59\% male, 10.8 \pm 0.5 years of age) provided complete and valid data during all 3 measurement times. Baseline sample characteristics are shown in Table 1. The prevalence of overweight/obesity was $14 \%$ and there were no significant differences in anthropometric characteristics between boys and girls. As expected estimated APHV was higher in boys compared to girls $(13.5 \pm 0.4$ vs. $12.0 \pm 0.4$ years; $\mathrm{P}<0.001)$. There was also a high consistency across the three measurement time points in estimated APHV with a mean variance of 0.002 and $<0.001$ years for girls and boys, respectively.

Boys displayed better results at the $20 \mathrm{~m}$ sprint $(\mathrm{P}=0.002)$, sit ups $(\mathrm{P}=0.005)$, standing long jump $(\mathrm{P}<0.001)$ and 6 -minute run $(\mathrm{P}<0.001)$ compared to girls based on raw performance scores. Using age- and sex-standardized scores, boys were better than girls at the $20 \mathrm{~m}$ sprint $(\mathrm{P}=0.047)$, stand and reach test $(\mathrm{P}=0.047)$ and balancing $(\mathrm{P}=0.013)$. Nevertheless, total motor competence scores did not differ significantly between boys and girls.

\section{Cross-sectional results}

There was a moderate inverse association between estimated APHV and BMIPCT in boys and girls $\left(r_{\text {girls }}=-0.395\right.$; $\left.\mathrm{r}_{\text {boys }}=-0.369 ; \mathrm{P}<0.001\right)$, indicating that early maturation was associated with higher body weight. Associations between estimated APHV and motor competence were weak. In girls, estimated APHV significantly correlated with push-ups $(\mathrm{P}=0.008)$ and distance covered during the 6-minute run $(\mathrm{P}=0.044)$ (Table 2), indicating lower performance with earlier maturation. After adjustment for body weight, the association between the 6-miute run and estimated APHV was no longer significant, while the association with push-ups remained significant $(\mathrm{P}=0.030)$. In boys, weak positive correlations were observed between estimated APHV and push-ups ( $\mathrm{P}=0.010)$, sit ups $(\mathrm{P}=0.023)$, 
Table 1 Sample characteristics at baseline

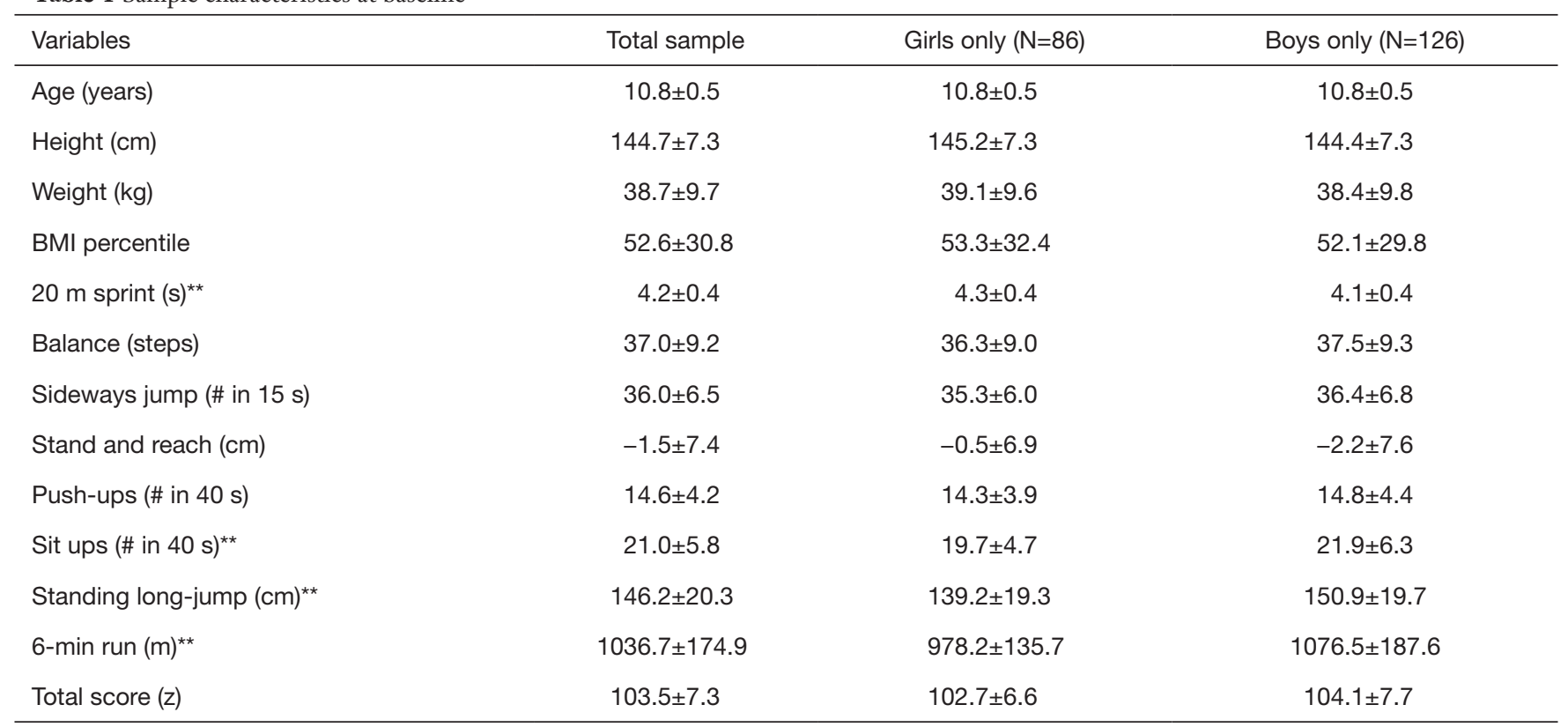

Values are mean $\pm \mathrm{SD}$. ${ }^{*}, \mathrm{P}<0.01$.

Table 2 Association between estimated age at peak height velocity and motor competence in boys and girls

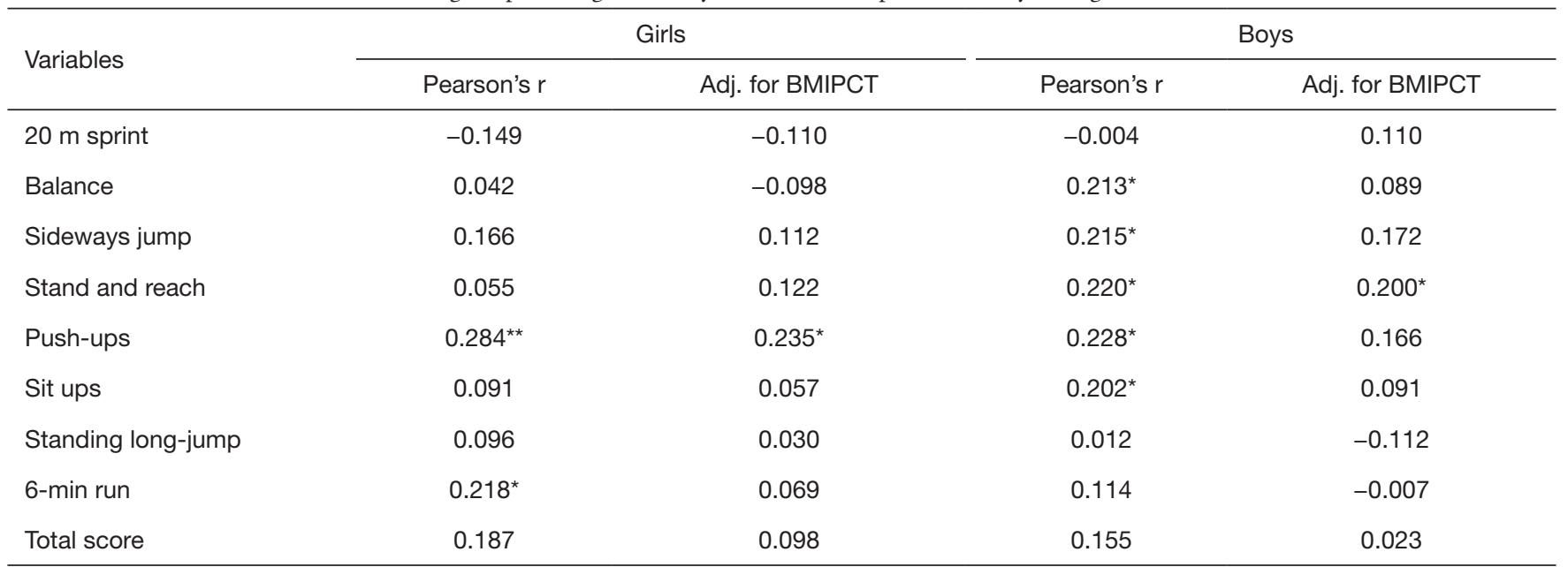

Values are Pearson's r. *, $\mathrm{P}<0.05 ;{ }^{*}, \mathrm{P}<0.01$.

sideways jumping ( $\mathrm{P}=0.015)$, flexibility $(\mathrm{P}=0.013)$ and balance $(\mathrm{P}=0.017)$. As was observed in girls, early maturation was associated with lower performance at these tests. After adjustment for BMIPCT, associations were no longer significant except for the stand and reach test (Table 2). No significant associations between estimated APHV and total motor competence was observed in either girls or boys.

\section{Longitudinal results}

Over the 3 -year observation period the prevalence of overweight/obesity increased from $14 \%$ to $18 \%$. Particularly, early maturing girls and late maturing boys showed a significant increase in BMIPCT $\left(\triangle \mathrm{BMIPCT}_{\text {girls }}=2.42 \pm 6.00 \mathrm{~kg} / \mathrm{m}^{2} /\right.$ year, $\mathrm{P}=0.046 ; \Delta \mathrm{BMIPCT}_{\text {boys }}=2.30 \pm 7.09 \mathrm{~kg} / \mathrm{m}^{2} /$ year, $\mathrm{P}=0.042$ ). Girls displayed significant improvements in sprint $(\mathrm{P}<0.001)$, 
Table 3 Annual change in motor competence over the 3-year observation period in boys and girls

\begin{tabular}{|c|c|c|c|c|}
\hline Variables & \multicolumn{2}{|r|}{ Girls } & \multicolumn{2}{|r|}{ Boys } \\
\hline$\Delta 20$ m sprint (s/year) & $-0.15 \pm 0.19^{\star \star}$ & $-0.18 \pm 6.00$ & $-0.15 \pm 0.18^{\star \star}$ & $1.04 \pm 5.29^{*}$ \\
\hline$\Delta$ Balance (steps) & $1.34 \pm 3.92^{\star \star}$ & $0.54 \pm 4.36$ & $1.17 \pm 3.90^{\star \star}$ & $0.45 \pm 4.37$ \\
\hline$\Delta$ Sideways jump (\# in $15 \mathrm{~s}$ ) & $4.52 \pm 2.77^{\star \star}$ & $3.27 \pm 4.49^{\star *}$ & $4.47 \pm 2.95^{\star \star}$ & $2.34 \pm 4.02^{\star \star}$ \\
\hline$\triangle$ Push-ups (\# in $40 \mathrm{~s}$ ) & $0.45 \pm 1.84^{*}$ & $0.16 \pm 5.43$ & $0.60 \pm 1.79^{\star \star}$ & $0.15 \pm 4.84$ \\
\hline$\Delta$ Sit ups (\# in $40 \mathrm{~s}$ ) & $0.50 \pm 2.49$ & $-0.91 \pm 3.97^{\star}$ & $1.17 \pm 2.47^{\star \star}$ & $-1.00 \pm 4.12^{\star \star}$ \\
\hline$\Delta$ Standing long-jump (cm) & $4.82 \pm 8.88^{\star \star}$ & $-0.67 \pm 3.62$ & $8.27 \pm 9.42^{\star \star}$ & $0.56 \pm 4.71$ \\
\hline$\Delta 6$-min run $(\mathrm{m})$ & $-10.15 \pm 50.29$ & $-2.62 \pm 4.08^{\star \star}$ & $-10.24 \pm 74.79$ & $-3.64 \pm 5.20^{\star *}$ \\
\hline
\end{tabular}

Values are mean \pm SD. $\Delta$, annual change based on mixed linear model; ${ }^{*}$, significant change at $\mathrm{P}<0.05$; ${ }^{* *}$, significant change at $\mathrm{P}<0.01$.

sideways jumping $(\mathrm{P}<0.001)$, balance $(\mathrm{P}=0.002)$, flexibility $(\mathrm{P}<0.001)$, standing long jump $(\mathrm{P}<0.001)$ and push-ups $(\mathrm{P}=0.027)$ (Table 3). Using sex- and age-standardized scores, only sideways jumping and flexibility improved significantly $(\mathrm{P}<0.001)$, while there was a decline in the performance for sit ups $(\mathrm{P}=0.036)$ and the 6-minute run $(\mathrm{P}<0.001)$, resulting in no significant change in total motor competence score. In boys, absolute performance improved in all test items $(\mathrm{P}<0.001)$ except for the 6-minute run (no change) and the stand and reach test, which declined significantly $(\mathrm{P}=0.032)$. Only sideways jumping $(\mathrm{P}<0.001)$ and sprint $(\mathrm{P}=0.029)$ improved based on sex and age-standardized values, while flexibility $(\mathrm{P}=0.045)$, sit ups $(\mathrm{P}=0.007)$ and 6-minute run performance $(\mathrm{P}<0.001)$ declined (Table 3$)$. As observed in girls there was no significant change in total motor competence score in boys.

When examining change in raw performance scores by maturity status, early maturers showed a significant improvement in balance $\left(\mathrm{P}_{\text {girls }}=0.016, \mathrm{P}_{\text {boys }}=0.004\right)$ (Table 4). In addition, there was a significant improvement in long jump performance in early $(\mathrm{P}=0.004)$ and average maturing girls $(\mathrm{P}=0.001)$ but not in their late maturing peers. Average maturing girls also showed an improvement in sit ups $(\mathrm{P}=0.043)$ and a decline in endurance $(\mathrm{P}=0.015)$ while there was no change in their early or late maturing peers. Late maturing boys displayed a significant decline in flexibility $(\mathrm{P}=0.037)$, which was not observed in early or average maturing boys.

Using sex- and age-standardized scores, late maturing boys displayed a significant decline in long jump performance $(\mathrm{P}=0.022)$ and flexibility $(\mathrm{P}=0.029)$, which contributed to a significant decline in total motor competence $(\mathrm{P}=0.022)$. No significant changes in motor competence were observed in early or average maturing boys (Figure 1). Late maturing girls showed a significant decline in long jump performance $(\mathrm{P}=0.013)$ and sit ups ( $\mathrm{P}=0.001)$ while no change was observed in their early or average maturing peers. In addition, late and average maturing girls displayed a significant decline in endurance capacity $\left(\mathrm{P}_{\text {late }}=0.002, \mathrm{P}_{\text {avg }}<0.001\right)$ (Figure 2).

\section{Discussion}

This study examined the association between motor competence and biological maturation in Austrian middle school students. Cross-sectional associations between biological maturation and motor competence were generally weak and indicated lower motor competence in early maturing adolescents. Early maturation, however, was also associated with higher body weight. As shown in previous studies there was an inverse association between body weight and motor competence (30-32) and once body weight was taken into consideration, cross-sectional associations between biological maturation and motor competence were limited. Biological maturation was further associated with weight change. Specifically, early maturing girls and late maturing boys displayed a more pronounced increase in body weight compared to their peers. The greater weight gain in late maturing boys potentially contributed to the decline in total motor competence in this group, which was attributed to a significant decline in endurance, power and flexibility. Endurance capacity 
Table 4 Annual change in motor competence over the 3-year observation period in boys and girls by maturity tertiles

\begin{tabular}{|c|c|c|c|c|c|c|}
\hline Variables & \multicolumn{3}{|c|}{ Girls } & \multicolumn{3}{|c|}{ Boys } \\
\hline$\Delta 20 \mathrm{~m}$ sprint (s/year) & $-0.15 \pm 0.19^{\star *}$ & $-0.19 \pm 0.17^{\star *}$ & $-0.12 \pm 0.21^{\star *}$ & $-0.16 \pm 0.21^{\star \star}$ & $-0.14 \pm 0.17^{\star \star}$ & $-0.14 \pm 0.15^{\star \star}$ \\
\hline$\Delta$ Balance (steps/year) & $2.13 \pm 4.30^{\star}$ & $0.45 \pm 3.15$ & $1.53 \pm 4.23$ & $1.92 \pm 4.03^{\star \star}$ & $0.93 \pm 4.05$ & $0.68 \pm 3.58$ \\
\hline$\Delta$ Sideways jump (\# in 15 s/year) & $4.87 \pm 2.05^{\star \star}$ & $3.56 \pm 3.44^{\star *}$ & $5.19 \pm 2.36^{\star \star}$ & $4.82 \pm 2.83^{\star *}$ & $4.52 \pm 2.60^{\star *}$ & $4.05 \pm 3.38^{\star *}$ \\
\hline$\triangle$ Push-ups (\# in $40 \mathrm{~s} /$ year) & $0.74 \pm 2.12$ & $0.28 \pm 1.84$ & $0.34 \pm 1.58$ & $0.83 \pm 1.63^{\star \star}$ & $0.42 \pm 1.94$ & $0.55 \pm 1.81$ \\
\hline$\Delta$ Sit ups (\# in 40 s/year) & $0.69 \pm 2.58$ & $0.98 \pm 2.55^{\star}$ & $-0.17 \pm 2.26$ & $1.37 \pm 2.51^{\star \star}$ & $1.19 \pm 2.60^{\star \star}$ & $0.96 \pm 2.35^{\star}$ \\
\hline$\Delta$ Standing long-jump (cm/year) & $4.78 \pm 7.95^{\star \star}$ & $7.02 \pm 10.06^{\star \star}$ & $2.59 \pm 8.09$ & $11.33 \pm 10.34^{\star *}$ & $6.96 \pm 9.32^{\star \star}$ & $6.52 \pm 7.90^{\star \star}$ \\
\hline$\Delta 6$-min run (m/year) & $2.44 \pm 56.67$ & $-20.63 \pm 43.57^{\star}$ & $-11.02 \pm 49.58$ & $-8.25 \pm 93.12$ & $-13.94 \pm 62.36$ & $-8.52 \pm 66.88$ \\
\hline
\end{tabular}

Values are mean \pm SD. $\Delta$, annual change based on mixed linear model; *, significant change at $P<0.05$; **, significant change at $P<0.01$.

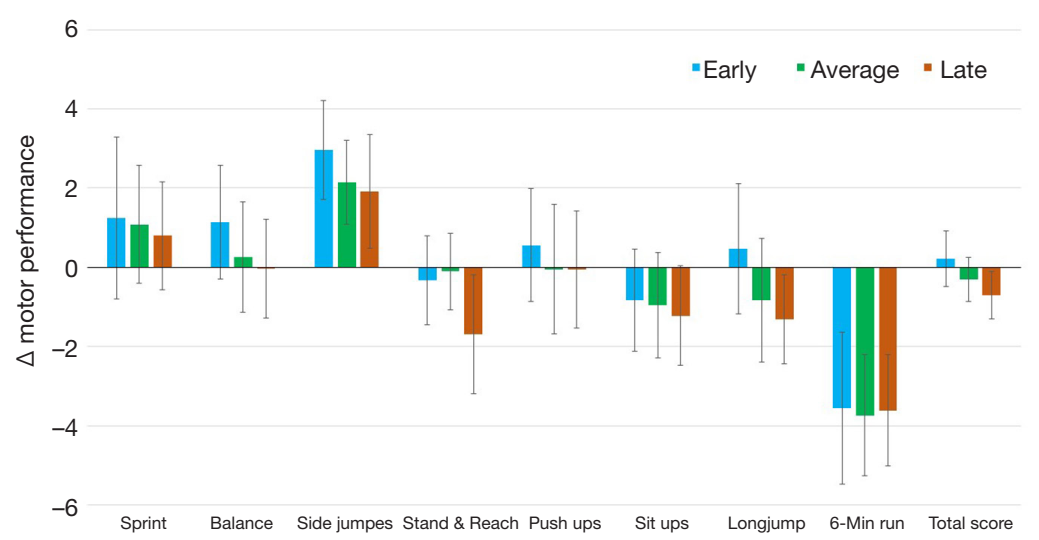

Figure 1 Annual change in age-standardized motor competence scores across the 3 -year observation period across maturity tertiles in boys. Values are means with $95 \%$ confidence intervals. $\Delta$, annual change based on mixed linear model.

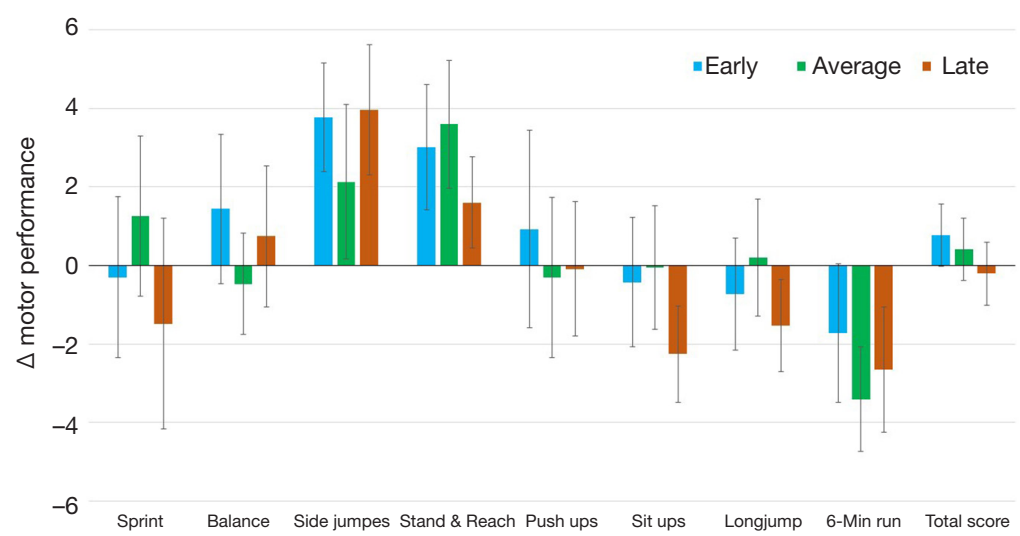

Figure 2 Annual change in age-standardized motor competence scores across the 3 -year observation period across maturity tertiles in girls. Values are means with $95 \%$ confidence intervals. $\Delta$, annual change based on mixed linear model. 
actually declined across all maturity tertiles in boys, while agility increased. Early maturing girls, on the other hand, did not show a decline in motor competence, despite their significant weight gain. Rather, late maturation was associated with a decline in power and endurance, while agility and flexibility increased across all maturity tertiles in girls.

Previous research also indicated a positive association between body weight and biological maturation $(33,34)$. In fact, it has been argued that higher body fat during childhood initiates earlier onset of maturation, particularly in girls $(33,35)$. Increased body weight has also been associated with less efficient movement forms and greater difficulty to perform various motor skills (11). Nevertheless, available research indicates that early maturing boys are more likely to be selected for various sports $(14,36)$. This has been attributed to hormonal changes during puberty that result in increased strength, which potentially provides a temporary advantage for early maturing boys over their average and late maturing peers (14). The present study, however, did not show any beneficial associations between early maturation and motor competence in boys when accounting for differences in body weight. Despite a greater muscular strength, early maturing boys may actually have a disadvantage during weight bearing tasks (due to the increased body weight), which were predominantly used in this study. A higher absolute strength in early maturing boys, however, could be an advantage during manipulative and object control tasks, which are key contributors to performance in many sports. The observed decline in motor competence along with a more pronounced increase in body weight in late maturing boys may also be an indicator for a greater risk of disengagement from sports and PA in late maturing boys, which has been reported previously $(14,37)$. Accordingly, late maturing boys potentially warrant special attention in the promotion of an active lifestyle as they may struggle in sports during adolescence, leading to anxiety and frustration (21), which results in reduced motivation towards participation in any form of PA later in life.

In girls, on the other hand, early maturation has been associated with an increased risk for disengagement from PA and sports (38-40). While this may partially be attributed to changes in personal and social interests, biological alterations need to be considered as well. Weight gain during maturation in girls has been associated with a higher accumulation of fat mass, which impairs participation in PA and physical fitness $(14,39,41)$. The cross-sectional results of the present study also showed lower motor competence with earlier maturation in girls, which was attributed to a higher body weight. Further, weight gain was more pronounced in early maturing girls, which could be an indicator for a greater disengagement from sports and PA. The change in body weight, however, did not affect the development of motor competence of early maturing girls. On the contrary, late maturing girls, rather than early maturing girls, displayed a significant decline in core strength and power. A possible explanation may be that late maturing girls experienced greater biological and psychological changes at the time of measurement as they were closer to their maturity offset during follow-up measurements, while early maturing girls were already further removed from their peak height velocity. During periods of rapid growth, various movement patterns may be disrupted and this could result in lower performance on various motor competence tests $(42,43)$. Further, Katzmarzyk et al. argue that neuromuscular maturation rather than strength affects motor performance (44), which may contribute to lower motor competence in late maturers.

In addition to the association between biological maturation and motor competence, the present study showed a decline in endurance capacity and core strength, independent of maturation, already in middle school students. Given the importance of these fitness parameters on cardiovascular health and general well-being this could have important implications for future health. Low cardiorespiratory fitness during childhood and adolescence has been associated with an increased risk for high blood pressure, abnormal blood lipids, adiposity and metabolic syndrome later in life (45). Similarly, low muscular fitness and motor competence at young ages have been associated with greater cardiovascular disease risk and adiposity later in life $(45,46)$. Accordingly, the promotion of physical fitness and motor competence via various movement experiences during childhood and adolescence appears to be a crucial component in efforts to improve public health. The present study further indicates a potential influence of biological maturation on the development of motor competence and physical fitness and, therefore, should be considered in the development of intervention strategies targeting an active and healthy lifestyle.

Even though this study provides interesting insights into the association between biological maturation and motor competence during early adolescence there are some limitations that should be considered when interpreting the results. The limited diversity in biological maturation may have affected the strength of the observed associations 
and the homogeneity of the study population may limit the generalizability of the results. There was also no objective assessment of PA, which is an important correlate of motor competence (47). Similarly there was no information on participation in organized sport, which could be of importance as alterations in body weight may provide advantages or disadvantages for sports performance, depending on the sport, and could affect motivation for a continued participation. The objective assessment of motor competence via a widely used and validated test battery along with the longitudinal nature of the study, on the other hand, are considerable strengths of this study. Multiple measurements around APHV also allowed for a more accurate estimation of maturity status as estimated APHV is more accurately predicted close to maturity offset (28). Nevertheless, estimations of biological maturation using somatic measures have been shown to be problematic, particularly in early and late maturers (48).

\section{Conclusions}

In summary, the present study indicates lower motor competence in early maturing adolescents due to their increased body weight. Late maturation, on the other hand, potentially impairs motor development, particularly in boys. This is of concern as low motor competence has been associated with an increased risk for disengagement from PA and drop out from sports along with the associated detrimental health effects later in life $(14,47)$. High motor competence, on the other hand, has beneficial effects on cognitive, social and emotional development (49-51). Puberty appears to be a particularly vulnerable period that is characterized by large biological changes along with alterations in social interests. It is also the time when various lifestyle habits start to develop (52), and, therefore, may provide important opportunities for the promotion of an active and healthy lifestyle. In order to develop adequate intervention strategies, individual differences in social, psychological and biological characteristics during the pubertal years, however, need to be considered. These differences may also increase the risk for disengagement from PA in specific subpopulations, which potentially warrant special attention. Accordingly, additional research on the association of biological maturation with motor competence is warranted. Particularly longer observation periods may be needed to account for a possible catch up in motor competence of late maturing adolescents. Further, a closer examination of differences in sports participation by biological maturation and benefits and disadvantages of early or late maturation in various sports could provide valuable insights for a more targeted approach in the promotion of PA and sports in youth.

\section{Acknowledgments}

None.

\section{Footnote}

Conflicts of Interest: The authors have no conflicts of interest to declare.

Ethical Statement: The authors are accountable for all aspects of the work in ensuring that questions related to the accuracy or integrity of any part of the work are appropriately investigated and resolved. The study has been carried out in accordance with the Declaration of Helsinki and procedures were approved by the University of Innsbruck Institutional Review Board (No. 16/2013), the school authorities of the federal state of Tyrol and the school board of the participating schools. Parents received written information about the study via the participating schools and provided written informed consent.

\section{References}

1. Janssen I, Leblanc AG. Systematic review of the health benefits of physical activity and fitness in school-aged children and youth. Int J Behav Nutr Phys Act 2010;7:40.

2. Kohl HW, Craig CL, Lambert EV, et al. The pandemic of physical inactivity: global action for public health. Lancet 2012;380:294-305.

3. Biddle SJ, Asare M. Physical activity and mental health in children and adolescents: a review of reviews. Br J Sports Med 2011;45:886-95.

4. Telama R. Tracking of physical activity from childhood to adulthood: a review. Obes Facts 2009;2:187-95.

5. Telama R, Yang X, Leskinen E, et al. Tracking of physical activity from early childhood through youth into adulthood. Med Sci Sports Exerc 2014;46:955-62.

6. Metcalf B, Henley W, Wilkin T. Effectiveness of intervention on physical activity of children: systematic review and meta-analysis of controlled trials with objectively measured outcomes (EarlyBird 54). BMJ 2012;345:e5888.

7. WHO. Global action plan on physical activity 2018- 
2030: more active people for a healthier world. Geneva, Switzerland: World Health Organisation, 2018:6-19.

8. Hardy LL, Barnett L, Espinel P, et al. Thirteen-year trends in child and adolescent fundamental movement skills: 1997-2010. Med Sci Sports Exerc 2013;45:1965-70.

9. Tomkinson GR, Olds TS. Secular changes in pediatric aerobic fitness test performance: the global picture. Med Sport Sci 2007;50:46-66.

10. Vandorpe B, Vandendriessche J, Lefevre J, et al. The KörperkoordinationsTest für Kinder: reference values and suitability for 6-12-year-old children in Flanders. Scand J Med Sci Sports 2011;21:378-88.

11. Hulteen RM, Morgan PJ, Barnett LM, et al. Development of Foundational Movement Skills: A Conceptual Model for Physical Activity Across the Lifespan. Sports Med 2018;48:1533-40.

12. Cliff DP, Okely AD, Morgan PJ, et al. The impact of child and adolescent obesity treatment interventions on physical activity: a systematic review. Obes Rev 2010;11:516-30.

13. Faigenbaum AD, Rial Rebullido T, MacDonald JP. The unsolved problem of paediatric physical inactivity: it's time for a new perspective. Acta Paediatr 2018;107:1857-9.

14. Malina RM, Bouchard C, Bar-Or O. Growth, maturation, and physical activity. 2nd ed. Champaign, IL: Human Kinectics, 2004.

15. Clark J, Metcalf J. The mountain of motor development: a metaphor. In: Clark J, Humphrey J. editors. Motor development: Research and reviews. Reston, VA: National Association of Sport and Physical Education, 2002:163-90.

16. Dishman RK, Dowda M, McIver KL, et al. Naturallyoccurring changes in social-cognitive factors modify change in physical activity during early adolescence. PLoS One 2017;12:e0172040.

17. Holfelder B, Schott N. Relationship of fundamental movement skills in physical activity in children and adolescents: A systematic review. Psychol Sport Exerc 2014;15:382-91.

18. Lloyd M, Saunders TJ, Bremer E, et al. Long-term importance of fundamental motor skills: a 20-year followup study. Adapt Phys Activ Q 2014;31:67-78.

19. Hardy LL, Reinten-Reynolds T, Espinel P, et al. Prevalence and correlates of low fundamental movement skill competency in children. Pediatrics 2012;130:e390-8.

20. Vandendriessche JB, Vandorpe B, Coelho-e-Silva MJ, et al. Multivariate association among morphology, fitness, and motor coordination characteristics in boys age 7 to 11 . Pediatr Exerc Sci 2011;23:504-20.

21. Brown KA, Patel DR, Darmawan D. Participation in sports in relation to adolescent growth and development. Transl Pediatr 2017;6:150-9.

22. Garcia C, Teles J, Barrigas C, et al. Health-related quality of life of Portuguese children and adolescents according to their biological maturation and volume of physical activity. Qual Life Res 2018;27:1483-92.

23. Hills AP, Byrne NM. An overview of physical growth and maturation. Med Sport Sci 2010;55:1-13.

24. Das JK, Salam RA, Thornburg KL, et al. Nutrition in adolescents: physiology, metabolism, and nutritional needs. Ann N Y Acad Sci 2017;1393:21-33.

25. Kromeyer-Hauschild K, Wabitsch M, Kunze D, et al. Perzentile für den Body-mass-Index für das Kindesund Jugendalter unter Heranziehung verschiedener deutscher Stichproben. Monatsschrift Kinderheilkunde 2001;149:807-18.

26. Bös K, Schlenker L, Büsch D, et al. Deutscher MotorikTest 6-18 (DMT6-18) [German motor abilities test 6-18 (DMT6-18)]. Hamburg, Germany: Czwalina, 2009.

27. Rogol AD, Clark PA, Roemmich JN. Growth and pubertal development in children and adolescents: effects of diet and physical activity. Am J Clin Nutr 2000;72:521S-8S.

28. Moore SA, McKay HA, Macdonald H, et al. Enhancing a Somatic Maturity Prediction Model. Med Sci Sports Exerc 2015;47:1755-64.

29. Cohen J. Statistical power analysis for the behavioral sciences. 2nd ed. Hillsdale, NJ: L Erlbaum Associates, 1988.

30. Lubans DR, Morgan PJ, Cliff DP, et al. Fundamental movement skills in children and adolescents: review of associated health benefits. Sports Med 2010;40:1019-35.

31. Cattuzzo MT, Dos Santos Henrique R, Ré AH, et al. Motor competence and health related physical fitness in youth: A systematic review. J Sci Med Sport 2016;19:123-9.

32. Barnett LM, Lai SK, Veldman SL, et al. Correlates of Gross Motor Competence in Children and Adolescents: A Systematic Review and Meta-Analysis. Sports Med 2016;46:1663-88.

33. Durda-Masny M, Hanć T, Czapla Z, et al. BMI at menarche and timing of growth spurt and puberty in Polish girls - longitudinal study. Anthropol Anz 2019;76:37-47.

34. Bratberg GH, Nilsen TI, Holmen TL, et al. Early sexual maturation, central adiposity and subsequent overweight in late adolescence. a four-year follow-up of 1605 adolescent Norwegian boys and girls: the Young HUNT study. BMC Public Health 2007;7:54.

35. Davison KK, Susman EJ, Birch LL. Percent body fat at age 5 predicts earlier pubertal development among girls at 
age 9. Pediatrics 2003;111:815-21.

36. Lovell R, Towlson C, Parkin G, et al. Soccer Player Characteristics in English Lower-League Development Programmes: The Relationships between Relative Age, Maturation, Anthropometry and Physical Fitness. PLoS One 2015;10:e0137238.

37. Cumming SP, Standage M, Gillison FB, et al. Biological maturity status, body size, and exercise behaviour in British youth: a pilot study. J Sports Sci 2009;27:677-86.

38. Drenowatz C, Eisenmann JC, Pfeiffer KA, et al. Maturityrelated differences in physical activity among 10 - to 12-year-old girls. Am J Hum Biol 2010;22:18-22.

39. Baker BL, Birch LL, Trost SG, et al. Advanced pubertal status at age 11 and lower physical activity in adolescent girls. J Pediatr 2007;151:488-93.

40. Wickel EE, Eisenmann JC. Maturity-related differences in physical activity among 13- to 14-year-old adolescents. Pediatr Exerc Sci 2007;19:384-92.

41. Ness AR, Leary SD, Mattocks C, et al. Objectively measured physical activity and fat mass in a large cohort of children. PLoS Med 2007;4:e97.

42. Patel DR, Pratt HD, Greydanus DE. Adolescent growth, development, and psychosocial aspects of sports participation: an overview. Adolesc Med 1998;9:425-40, v.

43. Beunen G, Malina RM. Growth and physical performance relative to the timing of the adolescent spurt. Exerc Sport Sci Rev 1988;16:503-40.

44. Katzmarzyk PT, Malina RM, Beunen GP. The contribution of biological maturation to the strength and

Cite this article as: Drenowatz C, Greier K. Association of biological maturation with the development of motor competence in Austrian middle school students-a 3-year observational study. Transl Pediatr 2019;8(5):402-411. doi: 10.21037/tp.2019.09.03 motor fitness of children. Ann Hum Biol 1997;24:493-505.

45. Ruiz JR, Castro-Piñero J, Artero EG, et al. Predictive validity of health-related fitness in youth: a systematic review. Br J Sports Med 2009;43:909-23.

46. Timpka S, Petersson IF, Zhou C, et al. Muscle strength in adolescent men and risk of cardiovascular disease events and mortality in middle age: a prospective cohort study. BMC Med 2014;12:62.

47. Stodden D, Goodway J, Langendorfer S, et al. A developmental perspective on the role of motor skill competence in physical activity: an emergent relationship. Quest 2008;60:290-306.

48. Kozieł SM, Malina RM. Modified Maturity Offset Prediction Equations: Validation in Independent Longitudinal Samples of Boys and Girls. Sports Med 2018;48:221-36.

49. Piek JP, Baynam GB, Barrett NC. The relationship between fine and gross motor ability, self-perceptions and self-worth in children and adolescents. Hum Mov Sci 2006;25:65-75.

50. Piek JP, Dawson L, Smith LM, et al. The role of early fine and gross motor development on later motor and cognitive ability. Hum Mov Sci 2008;27:668-81.

51. Skinner RA, Piek JP. Psychosocial implications of poor motor coordination in children and adolescents. Hum Mov Sci 2001;20:73-94.

52. Malina RM. Tracking of physical activity and physical fitness across the lifespan. Res Q Exerc Sport 1996;67:S48-57. 